\title{
Further Studies on Human Enteric Coronaviruses
}

\author{
By \\ E. O. CAUL ${ }^{1}$ and S. I. EgGrestont ${ }^{2}$ \\ 1 Public Health Laboratory, Bristol, England \\ 2 School of Environmental Sciences, Plymouth Polytechnic, Plymouth, England \\ With 6 Figures \\ Accepted February 4, 1977
}

\begin{abstract}
Summary
Comparisons were made between human enteric coronaviruses and the enteric coronaviruses of pigs and calves by negative staining.

Examination of human intestinal organ culture fluids at various time intervals after inoculation with the human enteric coronavirus showed increasing numbers of particles in the fluids.

Thin sections of the columnar epithelial cells of these explants showed a number of features consistent with the replication of known human and animal coronaviruses. Virus particles found in thin sections had a mean diameter of $68 \mathrm{~nm}$. In addition, a structure was found in thin sections which has not been described previously. This structure may represent the viral nucleocapsid.
\end{abstract}

\section{Introduction}

Human coronaviruses have been isolated in human foetal tracheal and nasal epithelium organ culture and in monolayer cell cultures $(1,4,10,12,16,20)$. Virions obtained from these cultures showed the typical coronavirus morphology by negative staining (3). Human coronaviruses have been studied extensively by negative staining of cell and organ culture fluids but until recently have not been seen or described in clinical material (6). Ultrastructural changes following replication of coronaviruses in cell cultures have been reported by a number of workers (15). However, there are no similar reports which describe ultrastructural changes following replication in human organ cultures. The present electron microscopical investigation was undertaken to study the morphology by negative staining of the newly described human enteric coronaviruses (5) and to compare them with two animal enteric coronaviruses, namely, transmissible gastroenteritis virus (TGEV) of pigs and neonatal calf diarrhoea virus. In addition observations were made on the ultrastructural changes associated with the replication of this human enteric coronavirus in human foetal intestinal organ cultures. Infection of the organ cultures with this non-laboratory adapted virus represents a model system as close 
as possible to the in vivo situation and it may be postulated that the changes which occurred in the organ cultures may also occur in the intact host.

\section{Materials and Methods}

\section{Preparation for Negative Staining Study}

Faecal emulsions prepared from faeces of patients with gastroenteritis were clarified using a bench centrifuge and the supernatants were centrifuged on a Sorvall RC2-B ultracentrifuge at $50,000 \times g$ for 2 hours. Organ culture fluids were ultracentrifuged in an identical manner to the faecal emulsions. Grids were prepared from the ultracentrifuged deposits and negatively stained with 1.5 per cent phosphotungstic acid at $\mathrm{pH}$ 6.5. All grids and sections were examined in an AEI/801 electron microscope.

The porcine coronavirus (tissue culture adapted TGE) was supplied by Dr. D. Garwes (A.R.C. Compton) as a partially purified sucrose gradient preparation. The bovine coronavirus was supplied by Dr. Janice Bridger (A.R.C. Compton) as an ultracentrifuged faecal emulsion deposit.

\section{Preparation and Infection of Organ Cultures}

Human foetal intestinal organ cultures were prepared from the small intestine of a 24 week foetus by the method of EGGLESTONE (8) and RUBENSTEIN and TYRRELL (19). These cultures were maintained in Leibovitz L-15 medium at pH 6.5, supplemented with 0.4 per cent bovine albumin, $2.0 \mathrm{~mm}$ glutamine and antibiotics, and incubated on a rocker platform at $35^{\circ} \mathrm{C}$ as described by DorIs et al. (7). Cultures on the rocker platform completed a full rocker eycle once every five minutes. Cultures were inoculated with $0.05 \mathrm{ml}$ of a 10 per cent faecal emulsion from patient $X(5)$. After absorption for one hour, one $\mathrm{ml}$ of $\mathrm{L}-15$ medium was added and explants and fluids were removed separately at 6 hourly intervals after infection. Fluids were frozen and stored at $-70^{\circ} \mathrm{C}$.

\section{Preparation of Ultrathin Sections}

Explants were fixed with a 2.5 per cent solution of glutaraldehyde in $0.1 \mathrm{M}$ cacodylate buffer and post fixed with 1.0 per cent osmium tetroxide in buffer for one hour. After fixation they were dehydrated in a graded series of ethanol concentrations and flat embedded in araldite for thin sectioning. Sections were stained with uranyl acetate and lead citrate.

\section{Hesults \\ Negative Staining of Virus Particles \\ Virions in Faecal Emulsions}

Marked pleomorphism occurred in the virions seen in the faecal emulsions, although the majority ranged in size, inclusive of projection, from 120 to $230 \mathrm{~nm}$. The virions had radiating projections (approximately $20 \mathrm{~nm}$ in length) giving the characteristic appearance of coronaviruses (Fig. 1A). All of the virions had thin radiating projections which possossed spherical or tear drop-like dilations at the distal end. Some of the particles had a T-shaped structure attached to the distal end of the projection (Fig. 1B).

Fig. 1, A--D. Electron micrographs of negatively stained human enteric coronaviruses. Virus particles from faecal emulsion showing $A$. thin radiating projections with spherical or tear drop-like dilatations at the distal end and B. T-shaped structures at the distal end of the projection (arrowed). Virus particles from organ culture fluids C. and D., showing in $\mathrm{D}$. virion with reduced number of projections

E-F. Electron micrographs of negatively stained animal coronaviruses. E. porcine coronavirus $\mathrm{F}$. bovine coronavirus showing double fringe 

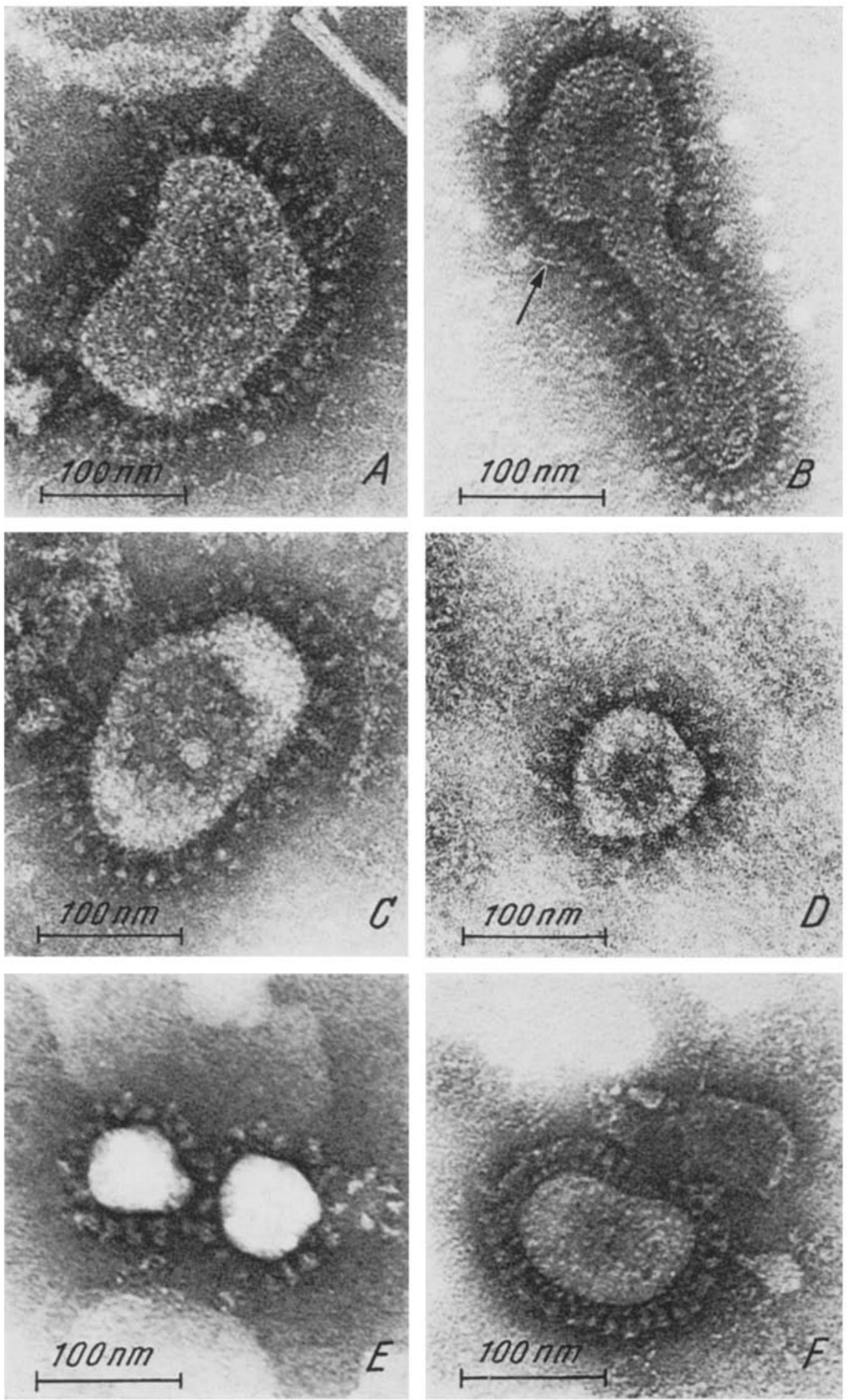

Fig. 1 A-F 


\section{Virions in the Organ Culture Fluids}

These virions were not as pleomorphic as those present in the faecal emulsions and the majority ranged in size from 100 to $200 \mathrm{~nm}$ (inclusive of projections). The projections on the surface of the virions were identical to those on the virions seen in the faecal emulsions with the exception that no T-shaped structures were observed (Fig. 1C). Some virions had lost many of the surface projections (Fig. 1D). There was a dramatic increase in the number of extracellular virions present in the 24 hours post-inoculation fluids compared with the 6 hours post-inoculation fluids. At 6 hours past-inoculation 27 particles were counted in five squares of a 250 mesh grid, whereas at 24 hours post-inoculation there were 243 particles in five grid squares. A typical field of the 24 hours fluid is shown in Figure 2. Of particular interest in the virions shown in Figure 1C,D and Figure 2 was the consistent appearance of the central electron-dense area. This has also been reported with other coronaviruses. However the virus envelopes appeared to be completely collapsed in the particles seen in the faeces (Fig. 1 A, 1 B).

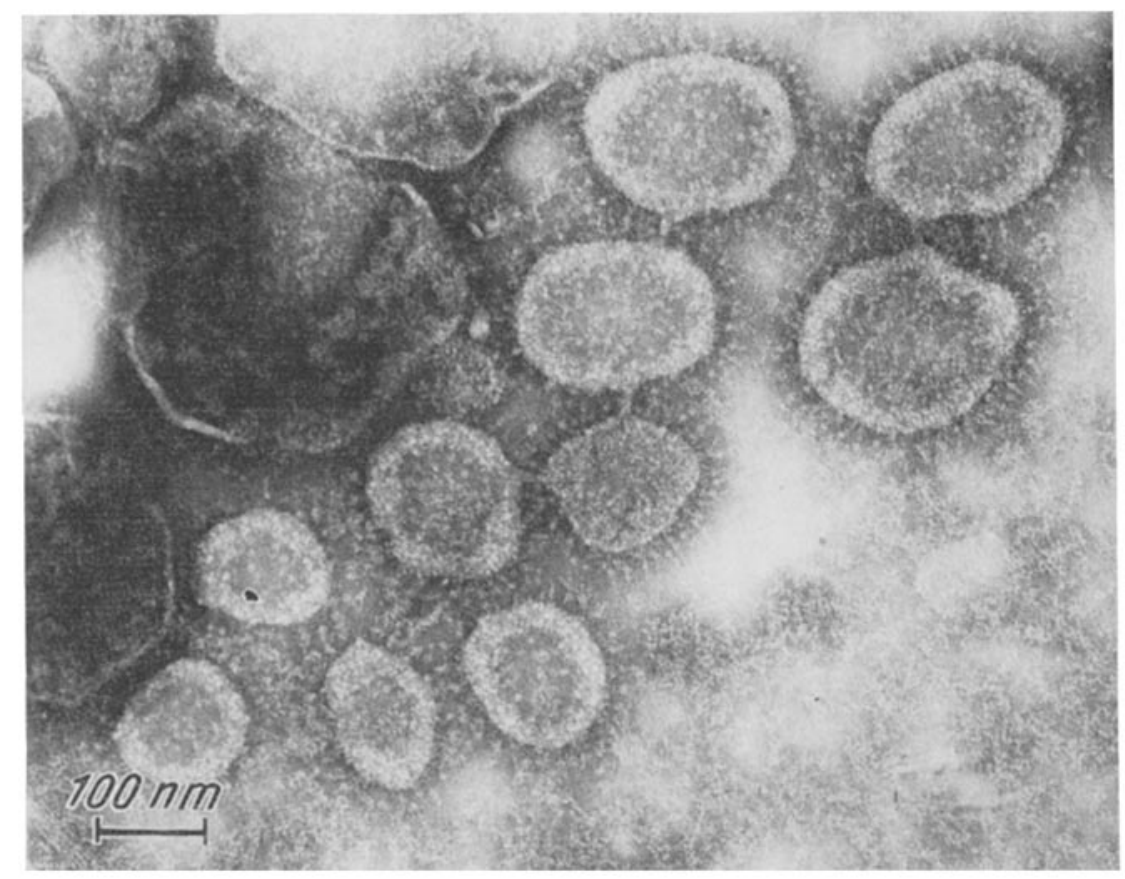

Fig. 2. Typical field seen in the 24 hours post-inoculation organ culture fluids

\section{Animal Coronaviruses}

Typical porcine and bovine coronavirus particles are shown in Figure $1 \mathrm{E}$ and 1 F respectively. Pleomorphism was present in both virus preparations. The bovine coronavirus particles commonly had two layers of projections giving the appearance of a double fringe (Fig. 1F). Projections of both viruses measured approximately $20 \mathrm{~nm}$. 

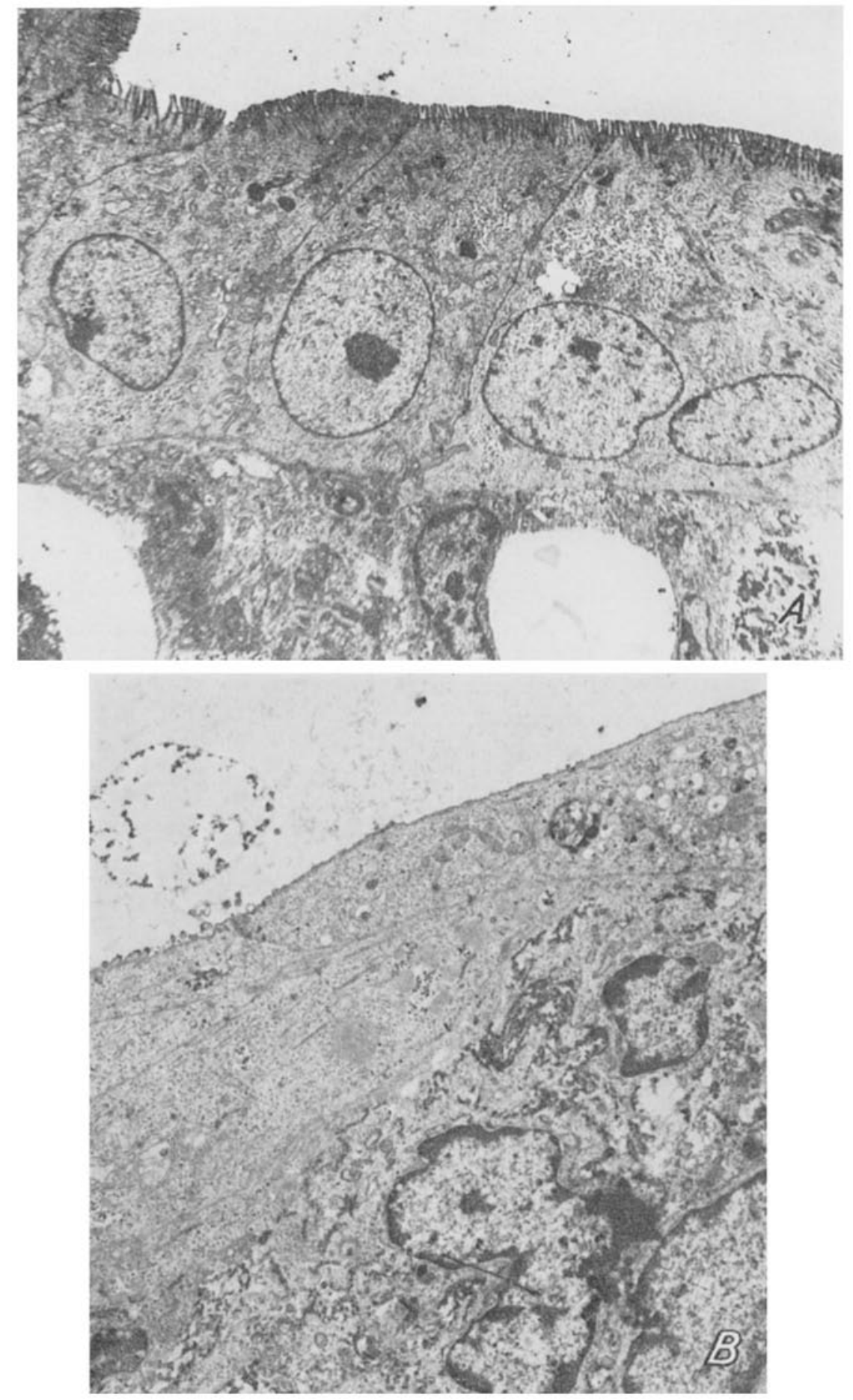

Fig. 3. Thin sections of human foetal intestine maintained in vitro

A. Normal appearance of uninfected cells. (Magnification $\times \mathbf{5 5 0 0}$ )

B. Virus infected culture showing complete loss of microvillous border. (Magnification $\times 25,000)$ 


\section{Electron Microscopy of Ultrathin Sections}

Preliminary work had indicated the localization of the virus in the columnar epithelial cells of the villi (5) so attention was focussed on these cells.

\section{Control Cultures}

The ultrastructure of the columnar epithelial cells of control cultures is shown in Figure $3 \mathrm{~A}$. These cells were characterized by a regular microvillous border,
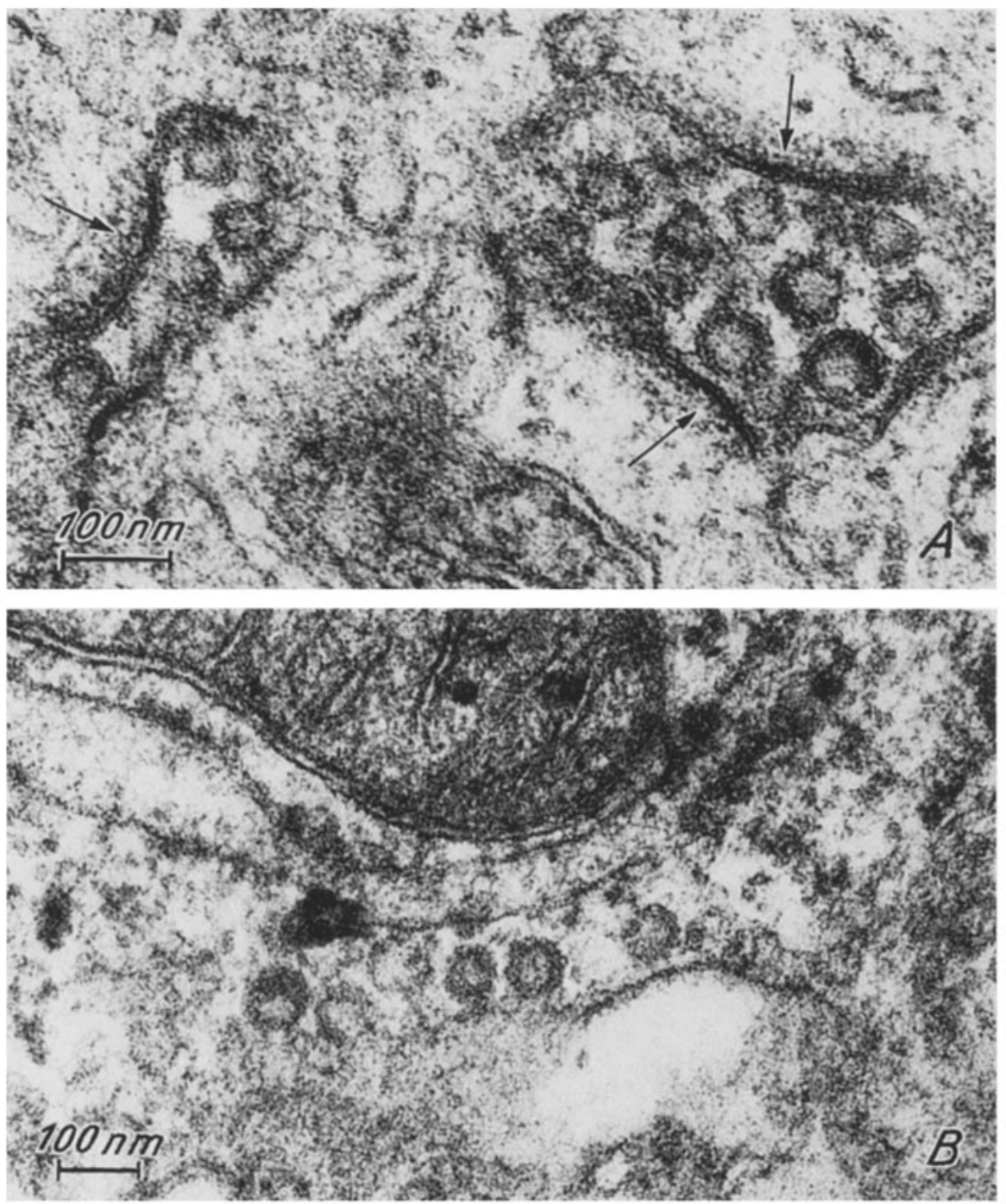

Fig. 4A. Cytoplasmic vesicle containing virus particles. Membranes with an underlying densely staining material are clearly seen bulging into the vesicle, (18 hours postinoculation)

B. Virus particles in the cisternae of the endoplasmic reticulum, 6 hours post inoculation) 

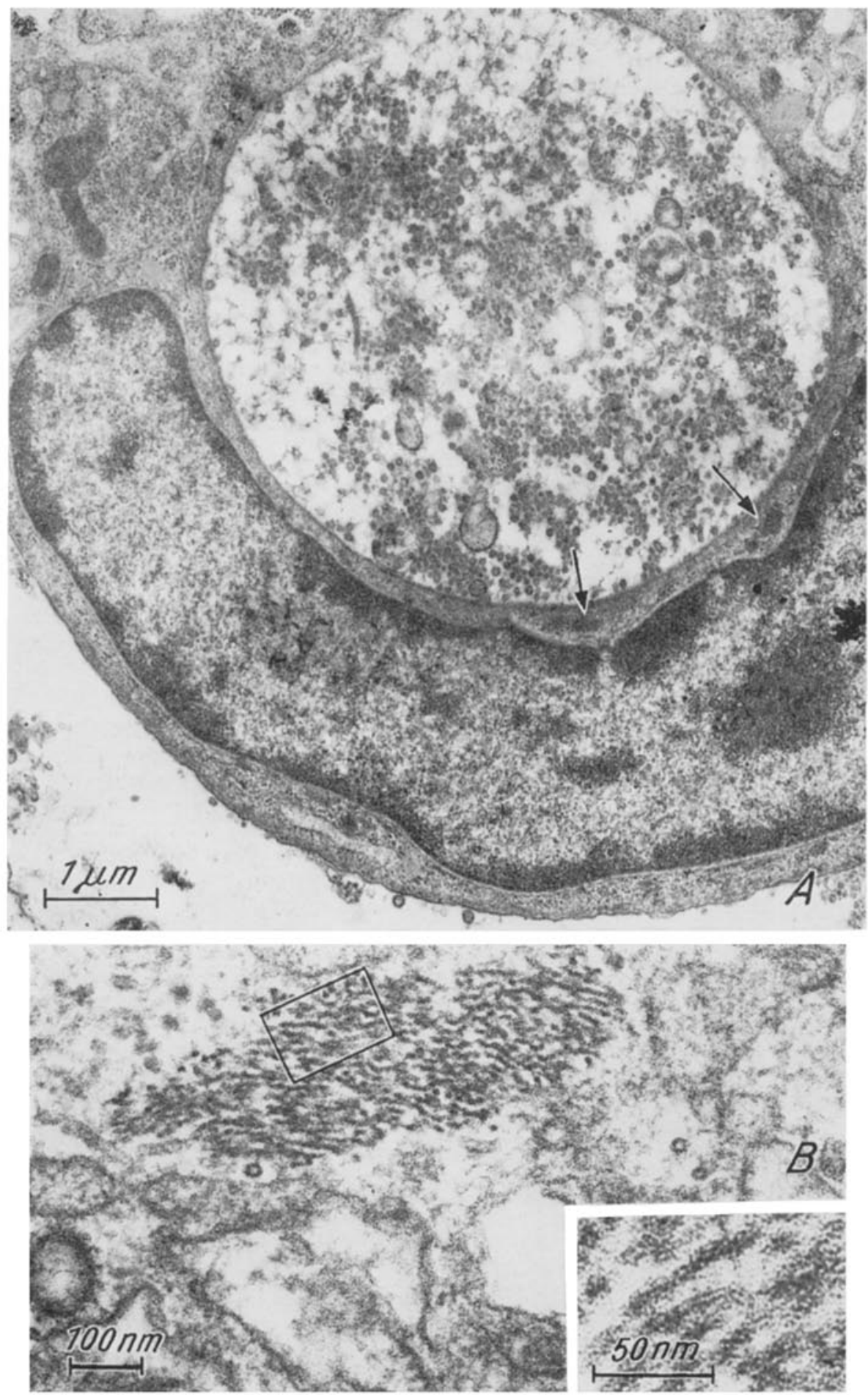

Fig. 5A. Columnar epithelial cell showing large virus containing vacuole and cytoplasmic filaments (arrowed), 12 hours post-inoculation

B. Cytoplasmic filaments, possibly viral nucleocapsids. Inset ... enlargement of enclosed area showing tubular nature of filaments 
a well-developed terminal web and endoplasmic reticulum, numerous mitochondria and basal nuclei. Multivesicular bodies were occasionally present in the apical cytoplasm. Cells at the base of the villi possessed short and irregular microvilli.

\section{Infected Cultures}

In the infected cultures some cells appeared normal whilst others showed marked changes. The most common changes were the complete loss of the microvillous border (Fig. $3 \mathrm{~B}$ ) and an increase in the number of ribosomes. Other changes included a reduction in the height of the columnar epithelial cells; consequently these cells appeared to have a markedly reduced cytoplasmic area terminal to the basal nuclei. Furthermore virus particles with an outer double membrane and having a mean diameter of $68 \mathrm{~nm}$ were found in the eytoplasmic vesicles and in the cisternae of the endoplasmic reticulum (Fig. $4 \mathrm{~A}$ and B). Thickened membranes with an underlying densely staining material are clearly seen bulging into the cisternae (Fig. 4A arrowed). Asymmetrical budding has not been observed. All these ultrastructural changes have been reported by McInTosh (15) during the replication of coronaviruses and were not present in any of the cells of the control cultures.

Occasionally columnar epithelial cells, in the late stage of desquamation, were seen protruding from the surface of the mid-villous region. In one such cell (Fig. 5A) there was a large membrane bound vacuole, basal to the nucleus, containing many virus particles. Close to this vacuole were bundles of filaments (Fig. 5A arrowed), which had a diameter of $9-10 \mathrm{~nm}$ and similar bundles were seen throughout the cytoplasm of infected cells (Fig. 5B) but never in non-infected cells. The tubular nature of these structures is clearly visible (Fig. 5B inset).

Cytoplasmic inclusion bodies were occasionally seen and they were composed of tubules with a mean diameter of $32 \mathrm{~nm}$. The tubules consisted of an electron-

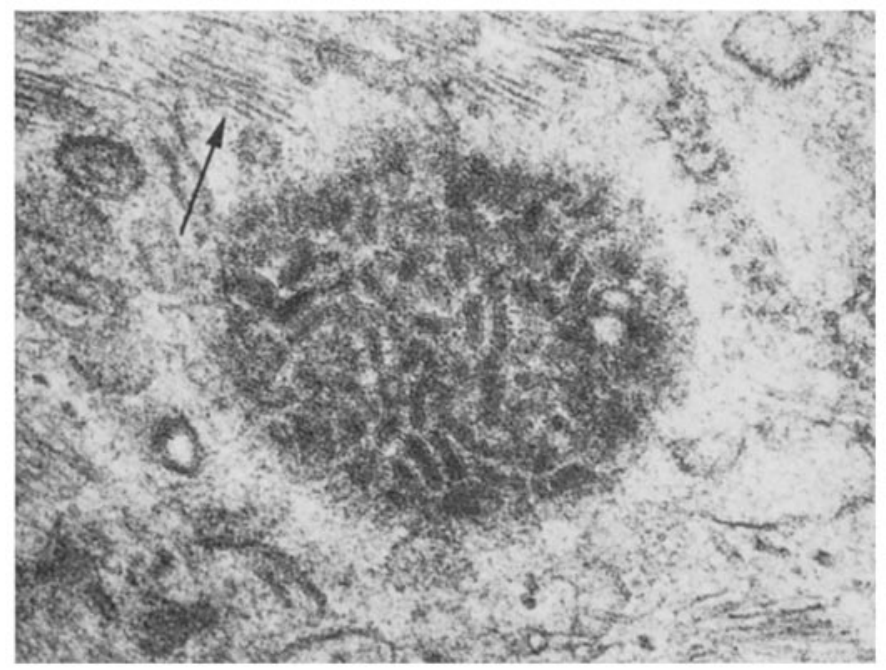

Fig. 6. Cytoplasmic inclusion body composed of tubules. Cytoplasmic microfilaments (arrowed), 18 hours post-inoculation 
dense core separated from further densely staining material by an electron translucent space (Fig. 6).

Possible virions were seen on the surface of the columnar epithelial cells (Fig. 5A), but budding from the cell surface was not observed. There was no evidence of any nuelear involvement.

\section{Discussion}

With the staining techniques employed in this study all the viruses examined showed the characteristic coronavirus morphology. However it was possible to distinguish between the viruses on the basis of morphology of the projections. The human viruses had thin rod shaped projections with a spherical or teardroplike dilatation at the distal end. The coronavirus-like particles deseribed by MATHAN et al. (14) appear to have a similar morphology (MATHar, personal communication). These thin projections were not seen on the porcine or bovine coronaviruses. This difference cannot be attributed to the staining procedure because identical methods were used.

Variation in the surface projections has been recognized with different strains of avian infectious bronchitis virus $(9,11)$. Both these groups reported projections of similar morphology to those described above for the human enteric corona. virus. Furthermore, morphological variation in TGEV projections has been described recently by RrTckue (18). All of the reports clearly show variation in the morphology of the $20 \mathrm{~nm}$ projections of known coronaviruses and in view of this the possession of classical petal shaped projection must no longer be considered a prerequisite for coronavirus identification.

It was not possible to infect the organ cultures under one step growth curve conditions and consequently we are not able to comment on the sequential dovelopment of the virus in this model system. The general appearance of virus particles in cytoplasmic vesicles and in the cisternae of the endoplasmic retioulum, and the absence of budding from the cytoplasmic membrane, is in agreement with published work on the morphogenesis of coronaviruses (15). The presence of particles in the cytoplasmic vesicles and the bulging of the membrane over underlying densely staining material are consistent with intracellular bud formation being the principle means of virus maturation.

The vacuole seen in Figure $5 \mathrm{~A}$ was possibly produced by the coalescence of small vesicles involved with virus budding. The cell containing the vacuole was undergoing desquamation and its disintegration would account for the large numbers of virions seen in the organ culture fluids at 24 hours post inoculation. The occasional non-membrane bound cytoplasmic inclusion bodies which were seen (Fig. 6) may represent viral precursors as suggested by OsHrRo et al. (17). The role of these tubular inclusions in the developmental cycle of the virus can only be ascertained by a sequential study.

Figure $5 \mathrm{~A}$ (arrowed) and $5 \mathrm{~B}$ show densely staining tubular filaments found only in infeeted cells. The diameter of these tilaments is larger than the diameter of cytoplasmic microfilaments commonly seen in non-infected and infected cells (Fig. 6 arrows). Furthermore they are much shorter in length. However, the diameter of these filaments $(9-10 \mathrm{~nm})$ is similar to that reported by Arostouov et al. 
(2) in thin sections of purified avian infectious bronchitis virions and to the recently described negatively stained nucleocapsids of human coronavirus $229 \mathrm{E}$ (13).

All of the ultrastructural changes described above, with the exception of the possible nucleocapsids, have been reported during the replication of coronaviruses. This evidence of replication is substantiated by the observation of a dramatic increase in the number of extracellular particles and the earlier report (5) of fluorescence in the columnar epithelial cells of the villi. Furthermore the changes described in this model system have also been recorded in intestinal columnar epithelial cells of animals infected with other coronaviruses. However, unlike the animal coronaviruses the exact role of the human enteric coronavirus in human gastroenteritis remains to be elucidated. This may prove difficult in view of the prolonged excretion of this virus in the faeces (unpublished observation). Volunteer studies may elucidate this problem.

\section{Acknowledgements}

We are grateful to Dr. S. K. R. Clarke, Dr. L. W. Greenham, Dr. T. J. Hill and Dr. W. K. Paver for advice and eritical reading of the manuscript and to $\mathrm{Mr}$. C. R. Ashley for the photographic work.

\section{Reierences}

1. Almeida, J. D., Tyrrext, D. A. J.: The morphology of three previously uncharacterized human respiratory viruses that grow in organ culture. J. gen. Virol. 1, $175-178$ (1967).

2. Apostolov, K., Flewetw, T. H., Kendal, A. P.: In: Barry, R. D., Mahy, B. H. W. (eds.), The Biology of Large RNA Viruses, 3-26. London: Academic Press 1970.

3. Berry, D. M., Cruickshank, J. G., ChU, H. P., Wells, R. J. H. : The Structure of infectious bronchitis virus. Virology 23, 403 (1964).

4. Bradburne, A. R., Bynoe, M. L., Tyrreld, D. A. J. : Effects of a new respiratory virus in volunteers. Brit. med. J. 3, 767-769 (1967).

5. CAUL, E. O., Clarke, S. K. R.: Coronavirus propagated from patient with nonbacterial gastroenteritis. Lancet $\mathbf{i}, 853-854$ (1975).

6. Caut, E. O., Paver, W. K., Clarke, S. K. R.; Coronavirus particles in faeces from patients with gastroenteritis. Lancet $\mathbf{i}, 1192$ (1975).

7. Dolin, R., Blacklow, N. R., Malmgrex, R. A., Chaxock, R. M. : Establishment of human foetal intestinal organ cultures for growth of viruses. J. inf. Dis. 122, $227-231(1970)$.

8. EGGLESTONE, S. I.: Laboratory investigation into the aetiology of non-bacterial gastroenteritis. Ph.D. Thesis. University of Bristol (1968).

9. Estola, S., WECKström, P.: Electron microscopy of infectious bronchitis virus. Ann. Med. exp. Biol. Fenn. 45, 30-31 (1967).

10. Hanrex, D., Procknow, J. J.: A new virus isolated from the human respiratory tract. Proe. Soc. exp. Biol. Med. 121, 190-193 (1966).

11. Harkness, J. W., Braceweld, C. D.: Morphological variation among Avian Infectious Bronchitis Virus strains. Res. vet. Sci. 16, 128-131 (1974).

12. Kapinian, A. Z., Janes, H. D., JR., Kelly, S. J., Dees, J. H., Turner, H. C., Mclntosm, K., Km, H. W., Parnoti, R. H., Vinoent, M. M., Chanock, R. M.: Isolation from man of "avian infectious bronchitis virus-like" viruses (coronaviruses) similan to $229 \mathrm{E}$ virus, with some epidemiological observations. J. inf. Dis. 119, 282-290 (1969).

13. Kennedi, D. A., Johnson-Lussenburg, C. M.: Isolation and morphology of the Internal component of Human coronavirus, strain $229 \mathrm{E}$. Intervirology 6, $197-206(1976)$. 
14. Mathan, M., Mathan, V. I., Swaninathan, S. P., Yesudoss, S., Baker, S. J.: Pleomorphic virus-like particles in human faeces. Lancet i, 1068-1069 (1975).

15. Molntosi, K.: Coronaviruses: A comparative review. Curr. Top. Microbiol. Immunol. 63, 85-129 (1974).

16. MoIntosh, K., Dees, J. H., Becker, W. B., Kapikian, A. Z., Chanock, R. M.: Recovery in tracheal organ cultures of novel viruses from patients with respiratory disease. Proe. Nat. Aead. Sci. U.S.A. 57, 933 940 (1967).

17. Oshrbo, L. S., Schieble, J. H., Lennette, E. H.: Electron microseopic studies of coronaviruses. J. gen. Virol. 12, $161-168$ (1971).

18. RrTchie, A. E. : Morphology of TGE virus characteristic particles and their antigen-antibody complexes. Proceedings of the 4th international Pig Veterinary Society. Ames, Towa (1976).

19. Rubenstein, D., Tyrreil, D. A. J.: Growth of viruses in organ cultures of intestine. Brit. J. exp. Pathol, 51, $210-216(1970)$.

20. Tyrrele, D. A. J., Bynoe, M. L.: Cultivation of a novel type of common-cold virus in organ cultures. Brit. med. J. 1, 1467-1470 (1965).

Authors' address: E. O. Caur, Public Health Laboratory, Myrtle Road, Kingsdown, Bristol BS 2 8EL, England.

Received December 14, 1976 